\title{
Pengaruh Knowledge Management Dan Teknologi Informasi Terhadap Keunggulan Bersaing Dan Kinerja Universitas
}

\author{
Siti Samsiah, Evi Marlina dan Hendri Ali Ardi \\ Fakultas Ekonomi \& Bisnis Universitas Muhammadiyah Riau \\ Email: siti.samsiah@umri.ac.id
}

\begin{abstract}
This study aims to find whether there is influence of knowledge management and information technology on competitive advantage and performance of private universities in Pekanbaru. This research is a survey research with the technique of distributing questionnaires to teaching and employees. The sample used in this study amounted to 320 people consisting of 222 teaching and 98 employees. Hypotheses were tested using Partial Least Square with SmartPLS version 2.0 software. The results of testing of the proposed hypothesis show evidence that knowledge management has an influence on the competitive advantage and performance of private universities in Pekanbaru, but not with the information technology variables that show the results have no effect on the competitive advantage and performance of private universities in Pekanbaru.
\end{abstract}

Keywords: Performance university, knowledge management, information technology, competitive advantages.

\begin{abstract}
Abstrak: Penelitian ini bertujuan untuk mengetahui apakah terdapat pengaruh knowledge management dan teknologi informasi terhadap keunggulan bersaing dan kinerja universitas swasta di Pekanbaru. Penelitian ini merupakan penelitian survey dengan teknik penyebaran kuesioner kepada tenaga pendidik dan tenaga kependidikan. Sampel yang digunakan dalam penelitian ini berjumlah 320 orang yang terdiri atas 222 tenaga pendidik dan 98 tenaga kependidikan. Hipotesa diuji menggunakan Partial Least Square dengan software SmartPLS versi 2.0. Hasil pengujian terhadap hipotesis yang diajukan menunjukkan bukti bahwa knowledge management memiliki pengaruh terhadap keunggulan bersaing dan kinerja universitas swasta di Pekanbaru, namun tidak demikian halnya dengan variable teknologi informasi yang menunjukkan hasil tidak berpengaruh terhadap keunggulan bersaing dan kinerja universitas swasta di pekanbaru.
\end{abstract}

Kata kunci: Kinerja universitas, knowledge management, teknologi informasi, keunggulan bersaing.

\section{PENDAHULUAN}

Seiring dengan meningkatnya animo masyarakat untuk mengenyam pendidikan tinggi, berdampak pada meningkatnya jumlah perguruan tinggi di Indonesia, baik negeri maupun swasta. Banyaknya jumlah perguruan tinggi, disatu sisi memberikan dampak freedom of choices bagi pengguna, disisi lain menciptakan ranah persaingan yang semakin kompetitif diantara perguruan tinggi.

Dalam konteks realita, Perguruan Tinggi Negeri menjadi pilihan utama bagi sebagian besar calon pengguna. Perguruan Tinggi Negeri terposisikan sebagai institusi dengan kualifikasi kualitas diatas rata-rata Perguruan Tinggi Swasta. Positioning 
pengguna telah membawa peluang bagi hampir semua perguruan tinggi negeri dan menjadi tantangan bagi kebanyakan perguruan tinggi swasta. Menjadi tantangan karena menjadi opsi terakhir pengguna, yang mana tantangan tersebut berdampak pada banyak hal bagi perguruan tinggi swasta.

Rendahnya daya saing perguruan tinggi swasta atas perguruan tinggi negeri di sinyalir dikarenakan ketidakmampuan dalam mengidentifikasi keunggulan, disamping kinerja yang rendah. Keunggulan dan kinerja perguruan tinggi tercermin dari penilaian Direktorat Jenderal Pendidikan Tinggi dalam bentuk akreditasi institusi.

Untuk menciptakan keunggulan bersaing suatu organisasi harus memiliki sumber daya yang berbeda dari pesaingnya. Sumber daya yang dapat ditonjolkan salah satunya adalah sumber daya pengetahuan (knowledge). Pengelolaan knowledge management merupakan strategi bagi perguruan tinggi untuk mengidentifikasi pengetahuanpengetahuan yang dimiliki sehingga tercipta nya keunggulan bersaing dapat meningkatkan kinerja perguruan tinggi secara keseluruhan.

Begitu juga dengan kinerja pada perguruan tinggi, yang akan mencapai hasil yang maksimal apabila didukung dengan teknologi informasi yang dimiliki. Pada era digital sekarang ini pemanfaatan teknologi informasi merupakan suatu tuntutan dan merupakan strategi yang sangat tepat untuk menciptakan keunggulan bersaing dan meningkatkan kinerja perguruan tinggi. Perguruan Tinggi dapat memanfaatkan teknologi informasi dalam berbagai aktivitas akademik seperti untuk pelayanan administrasi, sebagai perangkat untuk aktivitas belajar mengajar, alat komunikasi serta pemanfaatan teknologi informasi untuk memudahkan pengambilan keputusan.

Penerapan Knowledge Management dan teknologi informasi ke dalam sistem manajemen perguruan tinggi dilakukan sebagai upaya untuk memberikan pelayanan yang berkualitas dalam mendukung pelaksanaan Tridarma Perguruan Tinggi. Melalui konsep Knowledge Management dan penerapan teknologi informasi perguruan tinggi dapat melakukan proses penciptaan, inovasi, tranfer pengetahuan baru, dan menciptakan keunggulan bersaing di dalam perguruan tinggi yang pada akhirnya akan meningkatkan kinerja perguruan tinggi tersebut. Tujuan dari penelitian ini adalah untuk mengetahui pengaruh knowledge management dan teknologi informasi terhadap keunggulan bersaing dan kinerja universitas swasta di Pekanbaru. Rumusan masalah dalam penelitian ini adalah (1) Apakah knowledge management berpengaruh terhadap kinerja perguruan tinggi? (2) Apakah knowledge management berpengaruh terhadap keunggulan bersaing? (3) Apakah keunggulan bersaing berpengaruh terhadap kinerja perguruan tinggi? (4) Apakah teknologi Informasi berpengaruh terhadap keunggulan bersaing? (5) apakah Information technology berpengaruh terhadap kinerja perguruan tinggi?

\section{KAJIANTEORI}

Knowledge Management. Knowledge management merupakan pengelolaan dari pengetahuan perusahaan dan aset intelektual yang dapat meningkatkan karakteristik kinerja organisasi dan nilai tambah dengan memungkinkan suatu perusahaan untuk bertindak lebih cerdas (Khan, 2012).

\section{Knowledge Management Infrastructure}

a. Sumber Daya Manusia (Human resources). Di era sekarang, kekuatan perusahaan baik dari sisi ekonomi maupun produksi berada pada aset intelektual dan bukan aset berwujud (Quinn, 1992). Keberadaan sumber daya manusia merupakan salah satu 
promotor sebuah organisasi yang paling berpengaruh dari sebuah knowledge management, untuk itu knowledge management harus dimanfaatkan secara optimal.

$b$. Budaya manajemen pengetahuan (Knowledge management culture). Budaya pengetahuan didefinisikan sebagai budaya organisasi yang dapat mempengaruhi, menciptakan, dan transfer pengetahuan untuk kesejahteraan organisasi (Oliver dan Kandadi, 2006). Menurut Gholipour et al., (2010), untuk mengelola pengetahuan secara efektif dalam sebuah organisasi, budaya pengetahuan harus dipupuk.

\section{Knowledge Management Processes}

a. Acquisition. Akuisisi pengetahuan melibatkan proses yang mengarah untuk memperoleh pengetahuan. Aspek lain dari akuisisi pengetahuan adalah inovasi, yang merupakan proses menciptakan pengetahuan baru dari penerapan pengetahuan yang ada. Penggunaan pengetahuan dalam meningkatkan akuisisi pengetahuan baru adalah inti dari proses akuisisi pengetahuan (Inkpen \& Dinur, 1998).

b. Storage. Untuk memastikan bahwa data tetap aman, organisasi harus mengembangkan penyimpanan data yang tepat untuk keamanan data. Untuk memastikan perlindungan terhadap data dari penyalahgunaan, maka organisasi harus mendesain system keamanan untuk penyimpanan data.

c. Application. Nelson dan Winter (2002) menemukan bahwa aplikasi pengetahuan dilakukan ketika seorang individu atau unit kerja mempengaruhi perubahan perilaku di unit lain. Faktor penting dalam transfer pengetahuan adalah sejauh mana seorang individu tidak hanya memperoleh pengetahuan dari orang lain, tetapi juga menggunakan pengetahuan itu untuk melakukan / tugas sendirinya (Minbaeva et al., 2003).

Teknologi Informasi. Munculnya teknologi informasi saat sekarang ini telah membuka jalan terhadap peluang-peluang yang ada. Lee dan Hong (2002) menyoroti empat langkah dasar siklus manajemen pengetahuan yaitu; akuisisi pengetahuan, pengembangan pengetahuan, berbagi pengetahuan dan penerapan pengetahuan. Teknologi informasi memainkan peran penting dari siklus manajemen pengetahuan. Misalnya, sistem informasi dapat digunakan untuk pembuatan informasi, basis data online untuk menyimpan informasi dan jaringan untuk berbagi informasi.

Keunggulan Bersaing._Keunggulan bersaing didefinisikan sebagai kemampuan dari sebuah organisasi untuk membuat posisi tetap bertahan dari pesaing" (Li, Nathan, dan Rao; 2006). Keunggulan bersaing merupakan kemampuan yang memungkinkan organisasi untuk membedakan dirinya dari para pesaingnya (Tracey, Vonderembse, dan Lim, 1999; $\mathrm{Li}$, Nathan, dan Rao, 2006). Untuk mempertahankan posisi dari pesaing, perusahaan harus memiliki ciri khas yang membuat perusahaan tersebut berbeda dari pesaing, sehingga memberikan keunggulan dari pesaing (Tracey, Vonderembse, \& Lim., 1999)

Kinerja Universitas. Secara umum, kinerja Perguruan Tinggi dapat dilihat dari pelaksanaan Tri Dharma Perguruan Tinggi yaitu pendidikan dan pengajaran, penelitian, dan pelayanan kepada masyarakat. Jamil (2015), menunjukkan bukti bahwa kinerja perguruan tinggi diukur dengan penelitian dan produktivitas, komitmen karyawan, dan keterkaitan industri.

1. Penelitian dan produktivitas. Dalam era ekonomi pengetahuan, kegiatan penelitian di perguruan tinggi berada pada tataran cukup penting (Flagg et al., 2011. Hasil publikasi 
diakui sebagai ukuran kunci oleh badan akreditasi untuk peningkatan akreditasi dan menilai kualifikasi dosen (Koys, 2008).

2. Komitmen Karyawan. Komitmen karyawan di tempat kerja didefinisikan sebagai perasaan psikologis yang dirasakan oleh karyawan untuk organisasi dimana dia bekerja. Karyawan yang memiliki komitmen terhadap organisasi memiliki kecenderungan untuk percaya dan menerima tujuan yang ingin dicapai organisasi. Mereka setia dengan organisasi dan termotivasi untuk memberikan layanan terbaik kepada organisasi (Chen, 2007).

3. Keterkaitan Industri. Menurut Calaghiou at.,al (2001) hubungan universitas dengan industry dibentuk untuk mendapatkan keuntungan dalam memudahkan akses untuk memperoleh pengetahuan, seperti pemecahan masalah, pengembangan teknologi baru, meningkatkan reputasi perusahaan sebagai pasar tenaga kerja, dan meningkatkan peluang untuk memperoleh pendanaan dari perusahaan dalam bentuk corporate social responsibility.

Pengembangan Hipotesis. Menurut (Zaied, 2012), Knowledge management merupakan sebuah proses yang membantu organisasi untuk menemukan, memilih, mengatur, menyebarkan, dan mentransfer informasi penting dan keahlian yang diperlukan untuk kegiatan. Knowledge management merupakan formalisasi dan akses pengalaman, pengetahuan dan keahlian yang menciptakan kemampuan baru yang memungkinkan kinerja yang unggul, mendorong inovasi dan meningkatkan nilai pelanggan (Khan, 2012). Mills dan Smith (2011) meneliti dampak dari knowledge management pada kinerja perusahaan, hasil penelitian menunjukkan bahwa knowledge management berdampak pada kinerja perusahaan. Sedangkan Zaied, Hussein, dan Hassan (2012) meneliti knowledge management dalam perannya meningkatkan kinerja perusahaan pada beberapa perusahaan di Mesir, hasil penelitian nya menunjukkan hubungan positif antara knowledge management dan kinerja perusahaan. Berdasarkan kajian literatur yang ada, maka hipotesis yang diajukan dalam penelitian ini:

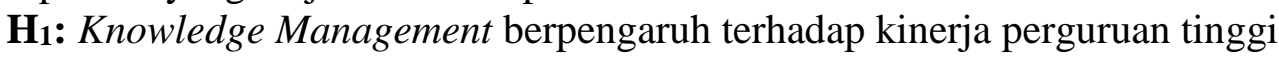

Implementasi Knowledge Management dalam bisnis menunjukkan bahwa knowledge management merupakan variabel penting dalam proses implementasi pembangunan keunggulan bersaing yang berbasis sumber daya (Carter dan Scarbrough, 2001). Organisasi yang mampu tumbuh dan berkembang membutuhkan modal, yaitu modal fisik dan modal virtual (human capital). Modal fisik merupakan kekayaan perusahaan berupa asset seperti mesin, peralatan, gedung, tanah, dan kekayaan fisik lainnya. Sedangkan modal virtual organisasi merupakan modal yang tidak berwujud dan tidak terukur sehingga sulit dicatat dalam akuntansi seperti intelectual capital. Dari hasil penelitian Devie (2013), menunjukkan bahwa knowledge management berpengaruh terhadap keunggulan bersaing pada perusahaan manufacture di Surabaya. Berdasarkan kajian literatur yang ada, hipotesis dalam penelitian ini:

H2: Knowledge management berpengaruh terhadap keunggulan bersaing

Li, B. Ragu-Nathan, T.S. Ragu-Nathan \& Rao (2006) menyatakan bahwa keunggulan bersaing mempunyai pengaruh positif terhadap kinerja perusahaan. Li, B. Ragu-Nathan, T.S. Ragu-Nathan \& Rao, mengukur keunggulan bersaing berdasarkan harga, kualitas, delivery dependability, inovasi produk dan time to market. Sedangkan kinerja perusahaan diukur berdasarkan kinerja berbasis pasar (Market performance) dan kinerja keuangan (financial performance). Berdasarkan hasil penelitian sebelumnya, hipothesis yang diajukan: 
H3: Keunggulan bersaing berpengaruh terhadap kinerja perguruan tinggi.

Teknologi informasi merupakan seperangkat teknologi yang digunakan oleh suatu organisasi untuk menghasilkan,proses, dan menyebarkan informasi dalam setiap bentuk.Oleh karena itu,teknologi informasi menyediakan dukungan untuk operasional perusahaan secaraefektif dan efisien. Keberadaan teknologi informasi memiliki peran strategisdalam meningkatkan dan menciptakan keunggulan dari pesaing. (Cakmak, P.I. \&Tas, E., 2012), dari hasil penelitiannnya menunjukkan bahwa teknologi informasi berpengaruh positif terhadap keunggulan bersaing. Berdasarkan literature yang ada , maka hipothesis yang diajukan adalah:

H4: Teknologi Informasi berpengaruh terhadap Keunggulan Bersaing

Penggunaan teknologi informasi dalam suatu organisasi telah diidentifikasi oleh banyak perusahaan sebagai alat penting untuk knowledge sharing organisasi dalam rangka meningkatkan kinerja organisasi. Hal ini digunakan sebagai strategi dan praktek yang digunakan organisasi untuk mengidentifikasi, menciptakan, mewakili, mendistribusikan, dan memungkinkan adopsi dari pengetahuan dan pengalaman (Kansal, 2011). Hasil penelitian Tanriverdi (2006) memperoleh bukti bahwa information technology relatedness berpengaruh positif dan signifikan terhadap kinerja perusahaan multibisnis. Atas dasar penelitian tersebut, maka hipothesis yang diajukan adalah:

H5: Information technology berpengaruh positif terhadap kinerja perguruan tinggi

\section{METODE}

Populasi, sampel, dan pengukuran variable. Populasi penelitian ini adalah seluruh tenaga pendidik dan kependidikan dengan rincian jumlah tenaga pendidik sebanyak 1,102 dan tenaga kependidikan sebanyak 484 yang tersebar pada empat universitas swasta di Pekanbaru. Sampel yang digunakan dalam penelitian adalah sebanyak 320 responden yang dihitung dengan menggunakan rumus slovin dengan taraf signifikan 5\%. Teknik pengumpulan data dengan menggunakan kuesioner. Variabel knowledge management diukur dengan dengan 18 item pertanyaan, variable kinerja universitas yang diukur dengan konstruk research dan productivity, employee commitment, dan industry linkage terdiri atas 11 item pertanyaan. Penelitian ini juga menambahkan variable teknologi informasi yang diukur dengan 6 item pertanyaan dan keunggulan bersaing diukur dengan 7 item pertanyaan.

Analisis Data. Analisis data dilakukan dengan menggunakan pendekatan Partial Least Square (PLS) dengan software SmartPLS versi 2. Langkah awal di dalam model PLS adalah membuat analisis jalur (path model). Analisis jalur dalam PLS menjelaskan hubungan antara variabel laten di dalam inner model dan hubungan antara variabel laten dan indicator di dalam outer model. Setelah melakukan estimasi model PLS, langkah selanjutnya adalah mengevaluasi seberapa baik model yang dibangun berdasarkan pada data sampel. Evaluasi diawali dengan evaluasi model pengukuran dan selanjutnya evaluasi model structural.

Evaluasi model pengukuran (outer model) menggunakan pendekatan reflektif. Evaluasi model reflektif terdiri:

a. Convergent Validity menggambarkan korelasi antara konstruk dengan indikatornya. Semakin besar korelasinya semakin baik. Ukuran reflektif dikatakan tinggi jika berkorelasi lebih dari 0,70 dengan konstruk yang ingin diukur. Namun demikian, 
untuk penelitian tahap awal dari pengembangan skala pengukuran nilai loading 0,5 sampai 0,6 dianggap cukup memadai (Chin, 1998 dalam Ghozali, 2006).

b. Composite Reliability menggambarkan konsistensi pertanyaan-pertanyaan dalam instrument. Composite Reliability dari blok indicator menunjukkan nilai yang memuaskan jika mempunyai $\geq 0.7$.

c. Discriminant validity adalah membandingkan nilai square root of Average Variance Extracted ( $A V E$ ) setiap konstruk dengan korelasi antara konstruk lainnya dalam model. Jika nilai akar $A V E$ setiap konstruk lebih besar daripada nilai korelasi antar konstruk dengan konstruk lainnya dalam model, maka dikatakan memiliki nilai discriminant validity yang baik. Pengukuran ini dapat digunakan untuk mengukur reabilitas component score variabel laten.

Setelah melakukan evaluasi outer model, langkah berikutnya adalah evaluasi Inner model. Pengujian inner model atau model struktural dilakukan untuk melihat hubungan antara variabel, nilai signifikansi dan R-square dari model penelitian. Penilaian model dengan PLS dimulai dengan melihat R-square untuk setiap variabel laten dependen. Perubahan nilai $\mathrm{R}$-square dapat digunakan untuk menilai pengaruh variabel laten independen tertentu terhadap variabel laten dependen apakah menpunyai pengaruh yang substantive (Ghozali, 2006).

\section{HASIL DAN PEMBAHASAN}

Tingkat Pengembalian Kuesioner dan Profil Responden. Universitas swasta yang dikirimi kuesioner berjumlah empat universitas, dan masing-masing universitas diberikan kuesioner sesuai dengan proporsional jumlah tenaga pendidik dan tenaga kependidikan. Dari 320 kuesioner yang disebarkan, kuesioner kembali sebanyak 283 (88,4\%). Dari kuesioner yang dapat diolah, berikut disajikan demografi responden

Tabel 1. Demografi Responden

\begin{tabular}{ll}
\hline Gender & Persentase (\%) \\
\hline Laki-laki & $44 \%$ \\
Perempuan & $56 \%$ \\
\hline Profil pekerjaan & \\
\hline Tenaga pendidik & $69 \%$ \\
Tenaga kependidikan & $31 \%$ \\
\hline Universitas & \\
\hline Universitas Islam Riau & $48 \%$ \\
Universitas Lancang Kuning & $27 \%$ \\
Universitas Abdurrab & $13 \%$ \\
Universitas Muhammadiyah Riau & $12 \%$ \\
\hline
\end{tabular}

Tabel 1 di atas memberikan gambaran karakteristik reponden berdasarka jenis kelamin, profil pekerjaan dan Institusi. Menurut jenis kelamin, responden terbanyak adalah perempuan dengan porsentase sebesar $56 \%$ atau setara dengan 158 orang dari 283 responden. Ditinjau dari profil pekerjaan, tenaga pendidik menjadi reponden terbanyak dibanding tenaga kependidikan dengan porsentase sebesar $69 \%$ atau setara dengan 195 orang dari 283 responden. Dan hampir sebagian besar responden bernaung di Universitas 
Islam Riau dengan porsentase sebesar $48 \%$ atau setara dengan 136 orang, dan sisanya bernaung pada tiga universitas swasta lainnya dengan porsentase rata-rata sebesar 17,33\%.

1. Deskripsi Variabel. Analisis data dilakukan terhadap 283 jawaban responden yang memenuhi criteria untuk dilakukan pengolahan data. Data yang diolah merupakan hasil rata-rata jawaban responden dari setiap variable penelitian.

Tabel 2. Deskripsi jawaban responden

\begin{tabular}{llll}
\hline Variable & $\mathrm{N}$ & Mean. & StdDev \\
\hline Knowledge Management & 283 & 0.6457 & 0.070 \\
Keunggulan Bersaing & 283 & 0.7491 & 0.054 \\
Teknologi Informasi & 283 & 0.7815 & 0.049 \\
Kinerja Universitas & 283 & 0.6798 & 0.059 \\
\hline
\end{tabular}

Dari tabel diatas diketahui bahwa Knowledge Management memiliki nilai standar deviasi paling besar diantara 3 variabel lainnya yaitu 0.070. Artinya sampel yang terlibat dalam memberikan jawaban untuk variabel tersebut lebih bervariasi dibandingkan ketiga variabel lainnya. Adapun variabel teknologi informasi dengan nilai standar deviasi yang kecil mengambarkan bahwa data sampel semakin homogen (hampir sama).

2. Analisa Data. Estimasi analisis jalur PLS Kinerja Universitas. Hasil estimasi PLS Kinerja Universitas dengan menggunakan SMARTPLS 2 dapat ditunjukkan dalam gambar 1 berikut.

Gambar diatas memberikan dua angka yang dapat dipergunakan dalam melakukan estimasi analisis jalur PLS. Angka pertama yaitu angka yang terdapat didalam lingkaran yang dikenal sebagai koefisien determinasi $\left(\mathrm{R}^{2}\right)$. Nilai koefisien determinasi sebesar 0.5384 pada variabel Kinerja Universitas menjelaskan bahwa variabel Knowledge Management, Teknologi Informasi, dan Keunggulan bersaing menjelaskan sebesar $53,84 \%$ varian variabel Kinerja Universitas.

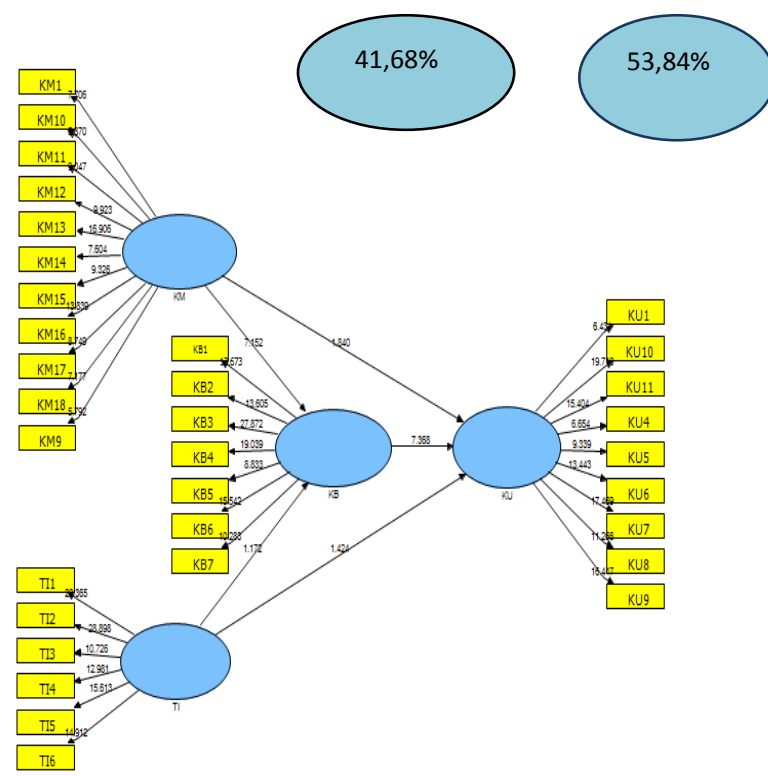

Gambar 1. Analisis Jalur PLS Kinerja Universitas 
Angka kedua yaitu angka di dalam anak panah yang dikenal sebagai koefisien analisis jalur. Dari gambar 1 didapati nilai Keunggulan Bersaing (7.368) mempunyai dampak paling besar terhadap Kinerja Universitas, kemudian diikuti oleh Knowledge Management (1.840) dan Teknologi Informasi (1.424)

a. Evaluasi Model Outer Model. Evaluasi outer model terdiri dari Internal Consistency; dan Discriminant Validity sebagaimana tertera pada tabel berikut:

Tabel 3. Composite Reliability

\begin{tabular}{lc}
\hline Variable & Composite Reliability \\
\hline Keunggulan Bersaing & 0.9012 \\
Knowledge Management & 0.8903 \\
Kinerja Universitas & 0.8900 \\
Teknologi Informasi & 0.9051 \\
\hline
\end{tabular}

Tabel 4. Square Root of Average Variance Extracted

\begin{tabular}{ll}
\hline Variable & $\sqrt{\text { AVE }}$ \\
\hline Keunggulan Bersaing & 0.7537 \\
Knowledge Management & 0.6534 \\
Kinerja Universitas & 0.6913 \\
Teknologi Informasi & 0.7844 \\
\hline
\end{tabular}

Tabel 5.Corelations of the Latent Variable

\begin{tabular}{lcccc}
\hline & KB & KM & KU & TI \\
\hline Keunggulan Bersaing & $\mathbf{0 . 7 5 3 7}$ & & & \\
Knowledge Management & 0.6401 & $\mathbf{0 . 6 5 3 4}$ & & \\
Kinerja Universitas & 0.7030 & 0.5927 & $\mathbf{0 . 6 9 1 3}$ & \\
Teknologi Informasi & 0.4864 & 0.6611 & 0.4996 & $\mathbf{0 . 7 8 4 4}$ \\
\hline
\end{tabular}

Internal consistency dengan composite reliability sebagaimana ditampilkan tabel 3 menunjukkan bahwa semua variabel yang diukur memiliki nilai composite reliability yang memuaskan karena bernilai lebih dari 0.7. Sedangkan tabel 4 adalah discriminant validity yang dinilai melalui Fornell Lacker (akar dari nilai AVE). Semua nilai Fornell Lacker adalah lebih besar dari nilai korelasi antara variabel laten sebagaimana yang tertera pada tabel 5. Berdasarkan kedua evaluasi tersebut maka dapat disimpulkan bahwa outer modelnya adalah valid sehingga tidak lagi perlu adanya penghilangan variabel indikator.

Inner Model. Pengujian inner model atau model struktural dilakukan untuk melihat hubungan antara konstruk, nilai signifikansi dan $R$-square dari model penelitian. Model struktural diuji dengan koefisien determinasi $\left(\mathrm{R}^{2}\right)$. Gambar 1 di atas, menunjukkan nilai $R$ square sebesar 0.5384 untuk variabel Kinerja Universitas. Artinya variabel Knowledge Management, Keunggulan Bersaing, dan Teknologi Informasi menjelaskan varian variabel Kinerja Universitas sebesar 53.84\%. Sedangkan variabel Knowledge Management dan Teknologi Informasi menjelaskan varian variabel Keunggulan Bersaing sebesar $41.68 \%$ $\left(\mathrm{R}^{2}=0.4168\right)$. 
Pengujian Hipothesis. Dasar yang digunakan dalam menguji hipotesis adalah nilai yang terdapat pada output result for inner weight. Untuk melihat apakah hipotesis yang diajukan dapat diterima atau ditolak, dapat dilihat besarnya nilai t-statistik yang dihasilkan. Batas untuk menolak dan menerima hipotesis yang diajukan dengan menggunakan $\alpha=5 \%$ dengan nilai t- sebesar 1,96. Apabila nilai t- kecil dari 1,96 maka hipotesis akan ditolak, atau dengan kata lain menerima hipotesis nol $\left(\mathrm{H}_{0}\right)$. Hasil estimasi tstatistik dapat dilihat pada result for inner weight pada tabel berikut:

Tabel 6. Result of Inner Weight

\begin{tabular}{lccccc}
\hline \multicolumn{2}{c}{ Keterangan } & Koefisien path & t-statistics & t-tabel & Kesimpulan \\
\hline H1 & KM -> KU & 0.4661 & 5.628 & 1,96 & Diterima \\
H2 & KM -> KB & 0,5657 & 7,152 & 1,96 & Diterima \\
H3 & KB -> KU & 0,5342 & 7,367 & 1,96 & Diterima \\
H4 & TI -> KB & 0,1125 & 1,172 & 1,96 & Ditolak \\
H5 & TI -> KU & 0,1315 & 1,424 & 1,96 & Ditolak \\
\hline
\end{tabular}

Hasil pengujian hiphotesis pertama menunjukkan bahwa variable knowledge management dengan keunggulan bersaing menunjukkan koefisien jalur sebesar 0,5657 dengan nilai $\mathrm{t}$ sebesar 7,152 lebih besar dari t table 1,96, yang berarti bahwa knowledge management memiliki hubungan yang positif terhadap keunggulan bersaing. Begitu juga denganpengujian hipothesis kedua menunjukkan pengaruh posistif antara variable knowledge management terhadap keunggulan bersaing ( $\left.t_{\text {hitung }} 7,15>t_{\text {table }} 1,96\right)$. Selanjutnya pada hipothesis ketiga menunjukkan pengaruh positif terhadap hubungan antara variable keunggulan bersaing dengan kinerja universitas dengan koefisien jalur 0,5342 dengan nilai t sebesar 7,3675 lebih besar dari t table 1,96. Sedangkan untuk hiphotesis keempat dan kelima tidak menunjukan pengaruh hal ini dapat dilihat dari hasil penghitungan dimana pada hiphotesis keempat thitung $1,172<\mathrm{t}_{\text {table }} 1,96$ dan hasil penghitungan hiphotesis kelima $\mathrm{t}_{\text {hitung }} 1,424<\mathrm{t}_{\text {table }} 1,96$.

Pembahasan. Dengan menggunakan program Smart PLS, hasil pengujian lima hiphotesis yang diajukan diperoleh hasil terdapat tiga hiphotesis yang diterima dan dua hipothesis ditolak. Adapun uraian hiphotesis yang diajukan adalah sebagai berikut:

1. Knowledge Management berpengaruh terhadap kinerja universitas swasta di Pekanbaru (H1 Diterima). Hipothesis pertama menyatakan bahwa knowledge management yang diukur dengan konstruk knowledge management infrastructure dan knowledge management processes secara signifikan berpengaruh terhadap kinerja universitas swasta di Pekanbaru, dengan demikian dapat disimpulkan bahwa universitas swasta yang melakukan praktek knowledge management yang tepat dan menganggapnya sebagai salah satu alat yang paling penting bagi organisasi maka akan mampu meningkatkan kinerja organisasi tersebut.

Hasil penelitian ini konsisten dengan penelitian yang dilakukan oleh Fifi dan Devie (2013) serta Raja dan Muhammad (2015). Hasil penelitian Fifi dan Devie (2013) menunjukkan bahwa knowledge management memiliki pengaruh sifnifikan terhadap kinerja perusahaan di Surabaya. Sedangkan Raja dan Muhammad (2015) meneliti praktek penerapan knowledge management untuk meningkatkan kinerja Universitas di Pakistan, hasil penelitiannya menunjukkan bahwa knowledge management memiliki pengaruh signifikan terhadap kinerja Universitas. 
2. Knowledge Management berpengaruh terhadap keunggulan bersaing (H2 Diterima). Berdasarkan hasil pengolahan data melalui PLS diketahui bahwa knowledge management memiliki pengaruh positif terhadap keunggulan bersaing pada universitas swasta di Pekanbaru. Hasil ini menunjukkan bahwa dengan adanya penerapan knowledge management mampu menciptkan keunggulan bersaing pada sebuah organisasi.

Hasil penelitian ini sejalan dengan penelitian yang dilakukan oleh Jasinskas, Svagzdiene Simanavicius (2014). Dari hasil kuesioner yang disebarkan kepada responden, hasil penelitian Jasinskas, Svagzdiene Simanavicius (2014) menunjukkan bahwa knowledge management berpengaruh signifikan terhadap keunggulan bersaing pada perusahaan manufacture di Lithuanian. Hasil penelitiannya menunjukkan bahwa tanpa knowledge yang tepat untuk melakukan pekerjaan sehari-hari, tujuan perusahaan tidak akan tercapai. Dengan artian bahwa knowledge mampu menciptakan keunggulan bersaing.

3. Keunggulan bersaing berpengaruh terhadap kinerja perguruan tinggi (H3 Diterima). Hasil pengujian hiphotesis ketiga menunjukkan bahwa keunggulan bersaing berpengaruh terhadap kinerja perguruan tinggi swasta di Pekanbaru. Keunggulan bersaing dapat diperoleh dari kemampuan perusahaan dalam mengelola sumber daya yang dimiliki. Perusahaan yang mampu menciptakan keunggulan bersaing akan memiliki kekuatan untuk bersaing dengan competitor lainnya karena produk maupun jasa yang diberikan kepada pelanggan memiliki daya tarik tersendiri. Dengan demikian, keunggulan bersaing akan mampu mendorong meningkatkan kinerja organisasi.

Hasil penelitian ini mendukung penelitian yang dilakukan oleh Fifi dan Devie (2013), yang menemukan bukti bahwa keunggulan bersaing berpengaruh terhadap kinerja perusahaan di Surabaya yang menerapkan knowledge management. Penelitian ini juga didukung oleh penelitian yang dilakukan oleh Li, Ragu-Nathan, Ragu-Nathan \& Rao (2006) yang menemukan bukti bahwa terdapat pengaruh antara keunggulan bersaing dengan kinerja perusahaan.

4. Teknologi Informasi berpengaruh terhadap Keunggulan Bersaing (H4 Ditolak). Pada penelitian ini, pengaruh teknologi informasi terhadap keunggulan bersaing tidak dapat dibuktikan memiliki pengaruh signifikan. Saat sekarang ini, teknologi informasi merupakan sebuah kebutuhan yang memberikan manfaat dan kemudahan bagi organisasi agar dapat mengakses informasi dan bukan sebagai strategis perusahaan untuk menciptakan persaingan. Fungsi teknologi informasi adalah terciptanya efisiensi untuk mengurangi pemborosan yang dilakukan oleh perusahaan (Moghavvemi 2012).

Hasil pengujian hipothesis pada penelitian ini sejalan dengan hasil survey yang dilakukan Cakmak (2012) pada perusahaan kontraktor di turkey. Cakmak (2012) melakukan sebuah penelitian untuk menentukan tingkat penggunaan teknologi informasi dan peran penting teknologi informasi dalam menciptakan keunggulan bersaing. Ditemukan bukti bahwa perusahaan tidak menjadi unggul dalam pesaingan dengan menggunakan teknologi informasi karena penggunaan teknologi informasi hanya menciptakan efek teknis dan ekonomi, bukan strategis. Dengan demikian perusahaan yang bersaing dalam bisnis perlu menggunakan teknologi informasi ditingkat strategis untuk mendapatkan keunggulan kompetitif.

5. Information technology berpengaruh positif terhadap kinerja perguruan tinggi (H5 Ditolak). Hiphotesis kelima pada penelitian ini menunjukkan hasil bahwa tidak terdapat pengaruh posistif hubungan information technology terhadap kinerja perguruan 
tinggi swasta di Pekanbaru. Penerapan teknologi informasi pada jaman sekarang sudah menjadi suatu kebutuhan dan memainkan peran strategi yang signifikan dalam suatu organisasi bukan sebagai perangkat untuk meningkatkan kinerja organisasi.

Hasil penelitian ini sejalan dengan penelitian yang dilakukan oleh Ra'ed (2013), yang meneliti dampak teknologi informasi terhadap kinerja perusahaan public di Jordania. Hasil penelitiannya menunjukkan bahwa tidak ada hubungan langsung antara teknologi informasi terhadap kinerja perusahaan, namun hubungan tersebut ditunjukkan melalui hubungan antara teknologi informasi dan keunggulan bersaing, dan keunggulan bersaing terhadap kinerja perusahaan.

\section{PENUTUP}

Simpulan. penelitian ini meneliti hubungan antara praktek knowledge management dan teknologi informasi terhadap keunggulan bersaing dan kinerja universitas swasta di Pekanbaru. Hasil penelitian menunjukkan bukti bahwa variasi variable knowledge management yang diukur dengan konstruk knowledge management infrastructure dan knowledge management process memiliki pengaruh terhadap keunggulan bersaing dan kinerja universitas swasta di Pekanbaru, dengan demikian dapat disimpulkan bahwa knowledge management memiliki peran penting dalam menciptakan keunggulan bersaing dan meningkatkan kinerja universitas swasta di Pekanbaru. Berbeda dengan pengujian hipothesis pengaruh variable teknologi informasi terhadap keunggulan bersaing dan kinerja universitas swasta di pekanbaru, yang menunjukkan hasil bahwa teknologi informasi tidak memiliki pengaruh terhadap keunggulan bersaing dan kinerja universitas swasta di Pekanbaru.

Saran. Dari hasil penelitian di sarankan kepada Universitas swasta agar dapat mendorong tenaga pendidik maupun tenaga kependidikan untuk terlibat dalam praktek knowledge management, karena dapat menciptakan keunggulan bersaing dan memainkan peran penting dalam meningkatkan kinerja universitas swasta khususnya di Kota Pekanbaru.

\section{DAFTAR RUJUKAN}

Agbim, K.C, Oriarewo, G.O \& Owutuamor, Z.B,. (2013). "The impact of knowledge management capability on organizational performance: A survey of the services sector". Journal of business management \& social sciences research (JMB \& SSR) 2 (9).

Bratianu, C., and Bolisani, E. (2015). "Knowledge strategy: An integrated approach for managing uncertainty. In Garlatti, A., and Massaro, M. (Eds.)", Proceedings of the 16th European Conference on Knowledge Management (pp.169-177). Reading: Academic Conferences and Publishing International.

Cakmak, P.I. \&Tas, E. (2012). "The Use of Information Technology on Gaining Competitive Advantage in Turkish Contractor Firms", World Applied Sciences Journal, 18 (2), 274-285.

Caloghirou, Y., Tsakanikas, A., \& Vonortas, N. S. (2001). University-industry cooperation in the context of the European framework programmes. The Journal of Technology Transfer, 26(1-2), 153-161. 
Carter, C., \& Scarbrough, H. (2001). "Towards a second generation of KM?: The People Management Challenge". Education + Training, 43 (4/5), 215-224.

Chan, J. O. (2014). "Integrating knowledge management and relationship management in an enterprise environment". Communications of the IIMA, 9(4), 4.

Chen, Y. J. (2007). "Relationships among service orientation, job satisfaction, and organizational commitment in the international tourist hotel industry". Journal of American Academy of Business, 11(2), 71-82.

El Bassiti, L., and Ajhoun, R. (2016). "Continuous Performance Improvement of Innovation: Bridging the Gap between Creativity and Measurement”. In Proceedings of the 28th International Business Information Management Conference (IBIMA) (pp.4248- 4262). Seville: IBIMA.

Flagg, D., Gilley, O. W., \& Park, J. C. (2011). ”Job Market Signaling: What Drives the Productivity of Finance Ph. Ds?", Financial Management, 40(2), 483-513.

Gholipour, R., Jandaghi, G., \& Hosseinzadeh, S. A. A (2010). "Explanation of knowledge management enabler as a latent variable: A case study of SMEs in Iran". Afr. J. Bus. Manage, 4(9).

Ghozali, Imam., (2006). Structural equation modelling Partial Least Square. Semarang: Badan Penerbit Universitas Diponegoro.

Ghozali, Imam., (2008). Structural equation modelling metode alternatif dengan Partial Least Square, edisi kedua. Semarang: Badan Penerbit Universitas Diponegoro.

Inkpen, A. C., \& Dinur, A. (1998). "Knowledge management processes and international joint ventures". Organization Science, 9(4), 454-468.

Jamil, R.A \& Lodhi, M.S.,(2015). "Role of knowledge management practices for escalating universities performance in Pakistan". Management science letters 5 (2015) 945-960.

Jasinskas, E, Svagzdiene, B, Simanavicius, A., (2015). "The influence of knowledge management on the competitive ability of Lithuanian enterprises". Procedia social and behavioral sciences, 191,. 2469-2475.

Kansal, Daisy, and Deepak Sengar. (2011). "Knowledge Management with Information Technology", International Journal of Information Technology and Knowledge Management, January-Jue 2011, 4 (1), 201-204.

Khan, R.A. (2012). "Knowledge Management: A Framework for Competitive Advantage". Global Journal for Information Technology and Computer Science, 1 (1).

Koys, D. J. (2008). "Judging academic qualifications, professional qualifications, and participation of faculty using AACSB guidelines". Journal of Education for Business, 83(4), 207-213.

Krawczyk Soltys, A. (2015). "Knowledge Management Processes in Polish Publice Hospitals Mapping of the Current Situation", Proceedings of the 11th international scientific conference on public economics and administration 2015, 2015, 95-100.

Kusuma, F.S.D dan Devie,. (2013). "Analisa pengaruh knowledge management terhadap keunggulan bersaing dan kinerja perusahaan”. Business accounting review, 1 (2).

Lee, S. M., \& Hong, S. (2002). "An enterprise-wide knowledge management system infrastructure". Industrial Management \& Data Systems, 102(1), 17-25.

Li, S., Ragu-Nathan, B., Ragu-Nathan, T.S., \& Rao, S.. (2006). "The impact of supply chain management practices on competitive advantage and organizational performance”. Omega, 34 (2), 107-124. 
Majeed, S., (2011). "The Impact of Competitive Advantage on Organizational Performance", International Journal of Business and Management, 3 (4), 191-197.

Massaro, M., Dumay, J., and Garlatti, A. (2015). "Public sector knowledge management: a structured literature review". Journal of Knowledge Management, 19(3), 530-558.

Mills, A. M., \& Smith, T. A., (2011). "Knowledge management and organizational performance: a decomposed view". Journal of Knowledge Management, 15(1), 156171.

Minbaeva, D., Pedersen, T., Björkman, I., Fey, C. F., \& Park, H. J. (2003). "MNC knowledge transfer, subsidiary absorptive capacity, and HRM". Journal of international business studies, 34(6), 586-599.

Moghavvemi, S., (2012). "Competitive Advantages Throught it Innovation Adoption by SMES", Journal Social Technologies, 7564 (1),24-39.

Nelson, R. R., \&Winter, S. G. (2002). "Evolutionary theorizing in economics". The journal of economic perspectives, 16 (2), 23-46.

Nguyen Q., Neck P., \& Nguyen T. (2008). "The Critical Role of Knowledge Management in Achieving and Sustaining Organizational Competitive Advantage". International Business Research, 2 (3), 3-16.

Oliver, S., \& Kandadi, K. R. (2006). "How to develop knowledge culture in organizations? A multiple case study of large distributed organizations". Journal of Knowledge Management, 10(4), 6-24.

Quinn, J. B. (1992). Intelligent Enterprise: A Knowledge and Service Based Paradigm for Industr: Simon and Schuster.

Ra'ed,. (2013). "The impact of information technology infrastructure flexibility on firm performance: An empirical study of Jordanian public shareholding firms", 9 (1).

Sumet, S., Suwannapong, N., How-teerakul, N., \& Thammarat, C. (2012). Knowledge management model for quality improvement in the hemodialysis unit for a non-profit private hospital, Bangkok, Thailand, Leadership in Health Services, 25 (4), 306-317.

Sun, R.S. and Van Ryzin, G.G. (2014). "Are performance management practices associated with better outcomes? Empirical evidence from New York public schools", American Review of Public Administration, 44(3), 324-38.

Tanriverdi, H. (2006). Performance Effects Of Information Technology Synergies In Multibusiness Firms, MIS Quarterly, Forthcoming.

Tavares, P.A. (2015). "The impact of school management practices on educational performance: evidence from public schools in Sao Paulo", Economics of Education Review, 48, 1-15.

Taylor, J. (2014). "Organizational Culture and the Paradox of Performance Management". Public Performance \& Management Review, 39(1), 7-22.

Titu, M., Oprean, C, Stan, S., and Titu, S. (2017). "The place and role of intellectual property policies in an advanced scientific research and education university". International Conference Knowledge-Based Organization, 23(1), 479-488.

Tracey, M., Vonderembse, M.A., \& Lim, J.S.. (1999). "Manufacturing technology and strategy formulation: keys to enhancing competitiveness and improving performance". Journal of Operations Management, 17, 411-28.

Utami, E. and Ali, I. (2012). Formulation of Company Strategy Based on Competitive Advantage, 11(2), 154-164. 
Wahyudin, W, (2015). “Analisis factor-faktor yang mempengaruhi keunggulan bersaing untuk meningkatkan kinerja perguruan tinggi swasta pada sekolah tinggi dan akademi di Semarang". Holistic journal of management research, 3 (2).

Wang, Z. and Wang, N. (2012). Knowledge sharing, innovation and firm performance, Expert Systems with Appiications, 39(10), 8899-8908.

Zaied, A.N.H. (2012). "An Integrated Knowledge Management Capabilities Framework for Assessing Organizational Performance". International Journal Information Technology and Computer Science, 2, 1-10.

Zaied, A. N. H., Hussein, G. S., \& Hassan, M. M., (2012). " The Role of Knowledge Management in Enhancing Organizational Performance". International Journal of Information Engineering and Electronic Business (IJIEEB), 4(5), 27. 